NASA/TM-2002-210724

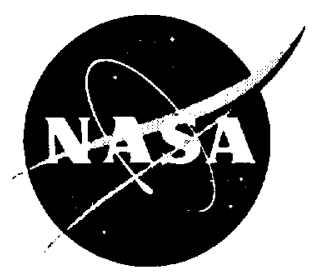

\title{
Ground and Flight Test Structural Excitation Using Piezoelectric Actuators
}

David Voracek

NASA Dryden Flight Research Center

Edwards, California

Mercedes C. Reaves and Lucas G. Horta

NASA Langley Research Center

Hampton, Virginia

Starr Potter

NASA Dryden Flight Research Center

Edwards, California 


\section{NOTICE}

Use of trade names or names of manufacturers in this document does not constitute an official endorsement of such products or manufacturers, either expressed or implied, by the National Aeronautics and Space Administration.

Available from the following:

NASA Center for AeroSpace Information (CASI)

7121 Standard Drive

Hanover, MD 21076-1320

(301) 621-0390
National Technical Information Service (NTIS) 5285 Port Royal Road Springfield, VA 22161-2171

(703) $487-4650$ 
NASA/TM-2002-210724

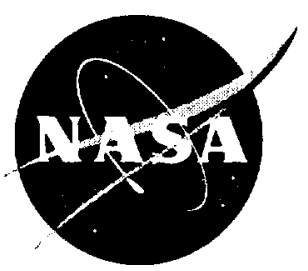

\section{Ground and Flight Test Structural Excitation Using Piezoelectric Actuators}

David Voracek

NASA Dryden Flight Research Center

Edwards, California

Mercedes C. Reaves and Lucas G. Horta

NASA Langley Research Center

Hampton, Virginia

Starr Potter

NASA Dryden Flight Research Center

Edwards, California

National Aeronautics and

Space Administration

Dryden Flight Research Center

Edwards, California 93523-0273 


\section{The NASA STI Program Office...in Profile}

Since its founding, NASA has been dedicated to the advancement of aeronautics and space science. The NASA Scientific and Technical Information (STI) Program Office plays a key part in helping NASA maintain this important role.

The NASA STI Program Office is operated by Langley Research Center, the lead center for NASA's scientific and technical information. The NASA STI Program Office provides access to the NASA STI Database, the largest collection of aeronautical and space science STI in the world. The Program Office is also NASA's institutional mechanism for disseminating the results of its research and development activities. These results are published by NASA in the NASA STI Report Series, which includes the following report types:

- TECHNICAL PUBLICATION. Reports of completed research or a major significant phase of research that present the results of NASA programs and include extensive data or theoretical analysis. Includes compilations of significant scientific and technical data and information deemed to be of continuing reference value. NASA's counterpart of peer-reviewed formal professional papers but has less stringent limitations on manuscript length and extent of graphic presentations.

- TECHNICAL MEMORANDUM. Scientific and technical findings that are preliminary or of specialized interest, e.g., quick release reports, working papers, and bibliographies that contain minimal annotation. Does not contain extensive analysis.

- CONTRACTOR REPORT. Scientific and technical findings by NASA-sponsored contractors and grantees.
- CONFERENCE PUBLICATION.

Collected papers from scientific and technical conferences, symposia, seminars, or other meetings sponsored or cosponsored by NASA.

- SPECIAL PUBLICATION. Scientific, technical, or historical information from NASA programs, projects, and mission, often concerned with subjects having substantial public interest.

- TECHNICAL TRANSLATION. Englishlanguage translations of foreign scientific and technical material pertinent to NASA's mission.

Specialized services that complement the STI Program Office's diverse offerings include creating custom thesauri, building customized databases, organizing and publishing research results...even providing videos.

For more information about the NASA STI Program Office, see the following:

- Access the NASA STI Program Home Page at http://www.sti.nasa.gov

- E-mail your question via the Internet to help@sti.nasa.gov

- Fax your question to the NASA Access Help Desk at (301) 621-0134

- Telephone the NASA Access Help Desk at (301) 621-0390

- Write to: NASA Access Help Desk NASA Center for AeroSpace Information 7121 Standard Drive Hanover, MD 21076-1320 


\title{
GROUND AND FLIGHT TEST STRUCTURAL EXCITATION USING PIEZOELECTRIC ACTUATORS
}

\author{
David Voracek ${ }^{*}$ \\ NASA Dryden Flight Research Center \\ Edwards, California \\ Mercedes C. Reaves ${ }^{\dagger}$ and Lucas G. Horta ${ }^{\ddagger}$ \\ NASA Langely Research Center \\ Hampton, Virginia \\ Starr Potter ${ }^{\S}$ \\ NASA Dryden Flight Research Center \\ Edwards, California
}

\begin{abstract}
A flight flutter experiment at the National Aeronautics and Space Administration (NASA) Dryden Flight Research Center, Edivards, California, used an 18-inch half-span composite model called the Aerostructures Test Wing (ATW). The ATW was mounted on a centerline flight test fixture on the NASA F-15B and used distributed piezoelectric strain actuators for in-flight structural excitation. The main focus of this paper is to investigate the performance of the piezoelectric actuators and test their ability to excite the first-bending and first-torsion modes of the ATW on the ground and in-flight. On the ground, wing response resulting from piezoelectric and impact excitation was recorded and compared. The comparison shows less than a 1-percent difference in modal frequency and a 3-percent increase in damping. A comparison of in-flight response resulting from piezoelectric excitation and atmospheric turbulence shows that the piezoelectric excitation consistently created an increased response in the wing throughout the flight envelope tested. The data also showed that to obtain a good correlation between the piezoelectric input and the wing accelerometer

\footnotetext{
* Research Engineer, AIAA Senior Member

${ }^{\dagger}$ Research Engineer, AIAA Member

\# Assistant Head, AlAA Associate Fellow

$\$$ Research Engineer, AIAA Member
}

Copyright 10202 by the American Institute of Aeronautics and Astronautics. Inc. No copyright is asserted in the United States under Title 17, U.S. Code. The U.S. Government has a royalty-free license to exercise all rights under the copyright claimed herein for Governmental purposes. All other rights are reserved by the copyright owner.
\end{abstract}

response, the input had to be nearly 3.5 times greater than the turbulence excitation on the wing.

\section{Nomenclature}

$\begin{array}{ll}\text { A } & \text { Ampere } \\ \text { ATW } & \text { aerostructures test wing } \\ \text { F } & \text { Farad } \\ \text { FEM } & \text { finite-element model } \\ g & \text { acceleration of gravity }\left(32.174 \mathrm{ft}^{2}{ }^{2}\right) \\ \text { GVT } & \text { ground vibration test } \\ \text { Hz } & \text { hertz (cycles per second) } \\ \text { KEAS } & \text { knots equivalent airspeed } \\ \text { LaRC } & \text { Langley Research Center, Hampton, } \\ & \text { Virginia } \\ \text { mV } & \text { millivolt } \\ \text { NACA } & \text { National Advisory Committee for } \\ & \text { Aeronautics } \\ \text { NASA } & \text { National Aeronautics and Space } \\ & \text { Administration } \\ \text { NASTRAN } & \text { NASA Structural Analysis Program } \\ \text { nF } & \text { nano-Farads } \\ \text { P } & \text { power consumption } \\ p & \text { poiver (one billionth of a Farad) } \\ \text { PT } & \text { piezoelectric-to-ratio turbulence } \\ \text { RMS } & \text { root mean square } \\ \text { sec } & \text { seconds } \\ \text { V } & \text { volt } \\ V p-p & \text { volt peak-to-peak } \\ \text { W } & \text { watt }\end{array}$




\section{Introduction}

Advanced materials and construction methods have led to vehicles that are lighter in weight but have less structural stiffness. This reduction in stiffness can result in the structure being more susceptible to structural dynamic problems, such as flutter. Aircraft flight tests can verify the absence of flutter in the operational envelope. During the flight test algorithms are used to estimate stability. The basic algorithm is designed to estimate frequency and damping at each flight condition. When the damping of a structure approaches zero, it can indicate instability. Damping is sometimes hard to estimate and good damping trends only begin to appear when the structure is close to instability. So new algorithms are being developed to improve the accuracy of predicting the onset of flutter.

A problem in validating a flight flutter prediction technique is that flight data near the onset of flutter instability is extremely challenging to obtain because of fight safety concerns. The Aerostructures Test Wing (ATW) is a fight experiment formulated by the National Aeronautics and Space Administration (NASA) Dryden Flight Research Center, Edwards, California. The ATW experiment generated flight data that can validate flight flutter prediction techniques. Testing of the ATW was designed to be similar to tests conducted for a new or modified aircraft. This testing included ground vibration testing and dedicated envelope clearance flights. The components of these flight tests included structural excitation, acquisition, and the analysis of the flight data. During these flight tests, the ATW was mounted on the NASA Dryden F-15B Flight Test Fixture. ${ }^{1}$ The objective of this ATW test was to fly the wing to the flutter instability threshold, while acquiring data that could be used in any flutter algorithm validation.

Structural excitation is an important requirement in flight flutter tests. Adequate excitation provides energy to excite all of the selected vibration modes at sufficient magnitudes to accurately assess stability from the response data. The excitation system must not only provide adequate force levels but must also [1] provide adequate excitation levels over the desired frequency range of interest, [2] be lightweight enough to not affect the modal characteristics of the structure, and [3] have power requirements that can be met by the aircraft. ${ }^{2}$
The piezoelectric actuators surface mounted on the wing met all of these design requirements by being lightweight, easy to install and use, and compatible with broadband excitation signals. NASA Langley Research Center (LaRC), Hampton, Virginia, and others, have conducted experiments with piezoelectric actuators to actively control the aeroelastic response and wing flutter ${ }^{3}$ and to suppress tail buffet. ${ }^{4,5}$ The Air Force Research Laboratory at Wright-Patterson AFB used Piezoceramic actuators to damp vibrations of a skin panel on a B-1B aircraft. ${ }^{6}$

The piezoelectric actuation system on the ATW was designed and built to excite the wing with adequate power above buffet excitation levels to allow structural modes to be observed during flight. The research discussed in this paper describes the excitation system components, and the ground- and flight-test results obtained using piezoelectric actuators, an impact hammer, and turbulence excitations.

\section{Wing Description}

The potential for the ATW to depart the aircraft as a result of flutter required an additional emphasis on a frangible design for aircraft and ground safety. The following four parameters were put into the design requirements for an excitation system for the ATW: excitation levels, power level, minimal weight, and frangible design.

Figure 1 shows a sketch of the Aerostructures Test Wing. The ATW was a National Advisory Committee for Aeronautics (NACA) 65A004 airfoil with a wing area of $197 \mathrm{in}^{2}$. The wing had a half-span of $18 \mathrm{in}$., a root chord of $13.2 \mathrm{in.}$ and a tip chord of $8.7 \mathrm{in}$. The total weight of the wing was $2.66 \mathrm{lb}$. The wing skin was made of three plies of fiberglass cloth, each $.015 \mathrm{in}$. thick, and the wing core was made of rigid foam. Internally there was a spar at the 30-percent chord line. The spar was made of graphite-epoxy and measured 1 ply, .005 in.-thick at its tip and 10 plies, .05 in.-thick at the root. The composite design of this ATW made it frangible. A 1-in. diameter boom (15-in. long), made of graphite epoxy, was attached to the wing. Inside the boom were three accelerometers for the ground and flight testing and the boom end-caps contained powdered tungsten for mass balancing. The wing was attached to the F-15B Flight Test Fixture (fig 2). 


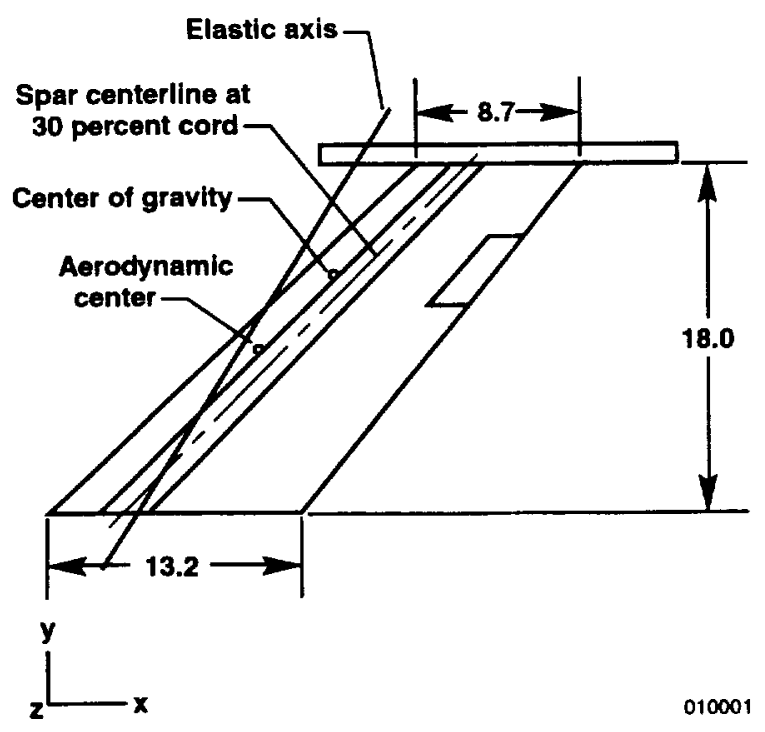

Figure 1: Aerostructures test wing sketch.

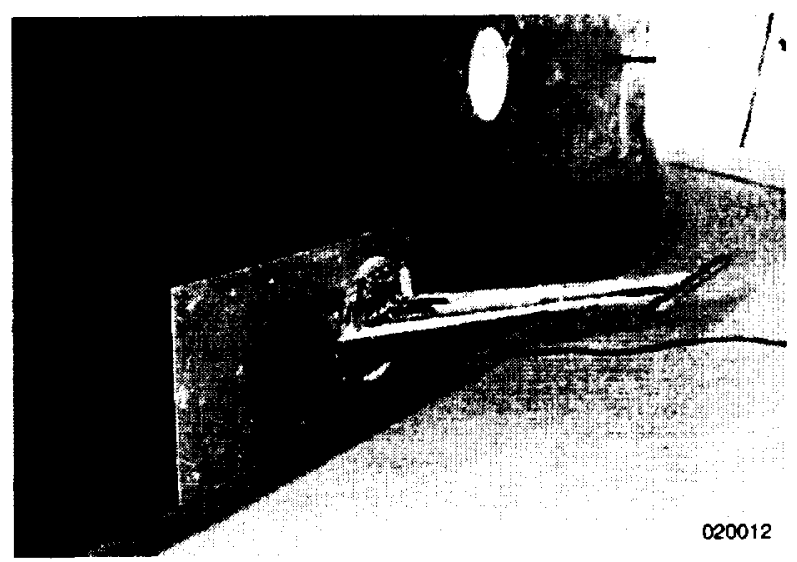

Figure 2: Aerostructures test wing on the flight test fixture.

\section{Wing Instrumentation}

Figure 3 shows the instrumentation layout for the ATW, which included three accelerometers and fourteen strain gages. The accelerometers provided the dynamic data that tracked flutter stability. Seven of the strain gages provided torque measurements and seven provided bending measurements. The strain gages were calibrated during ground tests to develop bending, shear, and torque equations for flight-test monitoring. The three accelerometers were located in the wingtip boom. Each accelerometer had a range of $\pm 50 \mathrm{~g}$, a sensitivity of $100 \mathrm{mV} / \mathrm{g}$, and a frequency range of $0.3 \mathrm{~Hz}$ to $12,000 \mathrm{~Hz}$. The aircraft instrumentation system provided a sample rate of 800 and 200 samples per sec for the accelerometers and strain gages. The strain gages and accelerometers were monitored and recorded real time during flight and ground tests.

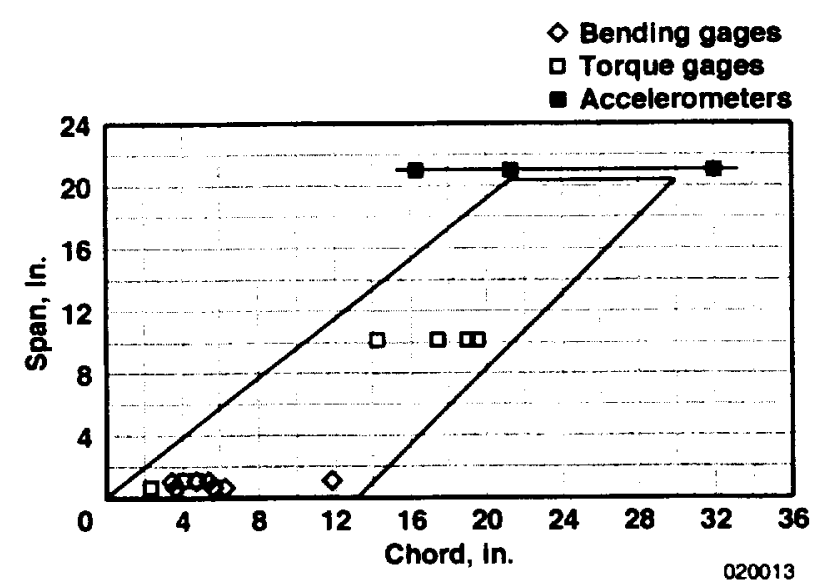

Figure 3: Instrumentation on the aerostructures test wing.

\section{Excitation System}

The excitation system design was subjected to the following system requirements or constraints:

1. The actuation system must be capable of broadband excitation, and sinusoidal sweeps and dwells, with a frequency bandwidth from $I$ to $100 \mathrm{~Hz}$.

2. A single channel of piezoelectric actuators must excite the first wing-bending mode and the first torsion mode of the ATW.

3. Stiffness and mass of the piezoelectric actuators must not change the first-bending mode and first-torsion mode frequencies by more than 5 percent.

4. The design for this excitation system must be frangible.

The final excitation system design consisted of four main components, the piezoelectric actuators, the amplifier, and the control computer, with a pilot interface box. A sketch of the system diagram is shown in figure 4 and photographs of the components are shown in figure 5 .

\section{Piezoelectric Actuators}

Piezoelectric actuators undergo a dimensional change when electric voltage is applied. When properly bonded these actutators can apply a strain to the surface. In this 


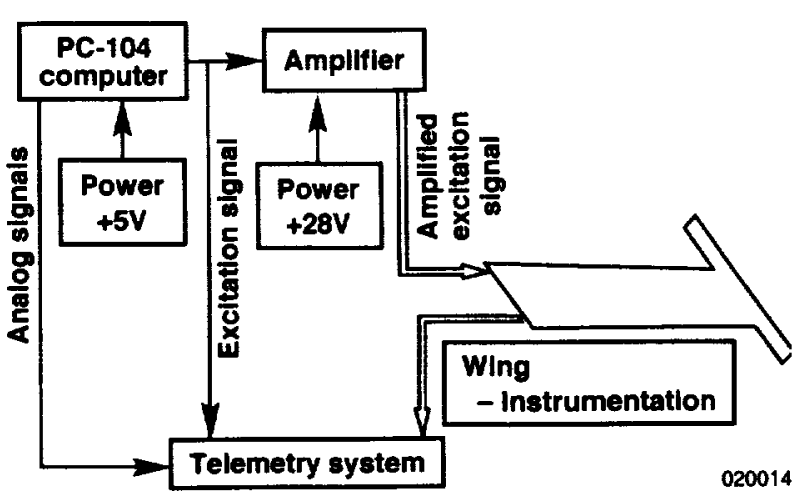

Figure 4: Diagram of ATW excitation system.

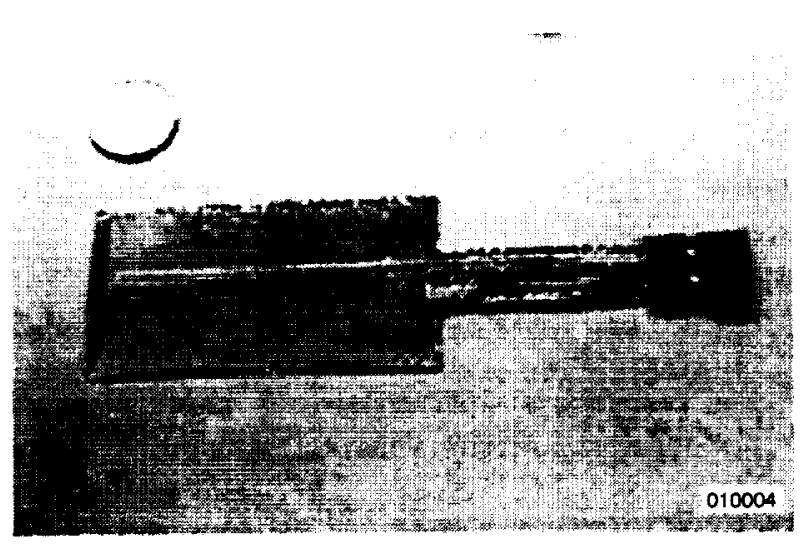

(a): piezoelectric actuator.
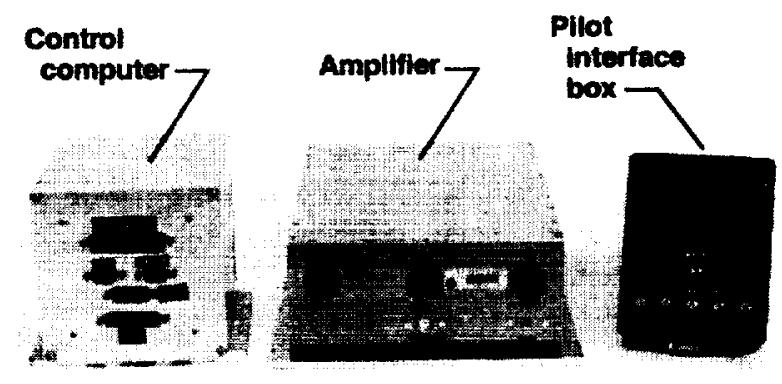

020015

(b): excitation hardware.

Figure 5: Piezoelectric excitation system.

mode, the piezoelectric actuators are a strain actuator. Piezoelectric actuators bonded to a structure can be joined together in a distributed actuator network with a minimal effect on the structural properties. ${ }^{7}$ The
Structural Dynamics Branch at NASA Langley Research Center (LaRC) designed and fabricated the piezoelectric actuators for the ATW. Specifically, the Langley work involved providing an optimized layout of piezoelectric actuators that would excite the first-bending mode and the first-torsion mode of the wing, and thus perform an analysis to estimate wingtip accelerations in response to expected excitations.

The piezoelectric patch selected for use on the ATW is shown in Figure 5a. Piezoelectric materials can be used in sensing and actuating applications. Piezoelectric devices used as sensors emit voltages when subjected to a mechanical load. In an actuating application, the piezoelectric effect is utilized as the actuators deform in response to a control signal or to applied voltage. The piezoelectric actuators were surface mounted to the ATW. The six patches on the wing were tied together electronically to create a single distributed strain actuator to excite the structural modes of the ATW.

The piezoelectric actuators had a maximum allowable input of 200 volts (V), but low power requirements. Power consumption for piezoelectric actuators can be calculated using the following equation: ${ }^{8}$

$$
P=\frac{1}{2} \omega_{\max } V_{\max }^{2} \sum_{i=l}^{n} C_{i}
$$

$$
\begin{gathered}
C_{i}=\text { effective capacitance of actuator } \mathrm{i} \\
n=\text { number of actuators being used } \\
\omega_{\max }=\text { maximum radial frequency } \\
V_{\max }=\text { maximum input voltage }
\end{gathered}
$$

For the ATW, there were six actuators with a capacitance of $183 \mathrm{nF}$, maximum voltage of $200 \mathrm{~V}$, and a maximum frequency of $35 \mathrm{Hertz}(\mathrm{Hz})$. Using the equation above, the piezoelectric actuators required about 4.8 watts (W) of power, which is close to 0.024 Amperes (A) at $200 \mathrm{~V}$. The strain actuator performance of the piezoelectrics used for the ATW was tested at NASA Langley Research Center. During this test, a piezoelectric actuator was instrumented with strain gages on the top and on the bottom. A $0.1 \mathrm{~Hz}$ sinusoidal signal at 200 Volts peak-to-peak ( $\mathrm{Vp}$-p) was applied to the patch and the free strain was measured. The test found that the patch performance has about a 
1.3 microstrains per volt. Mercedes Reaves from Langley made these measurements to evaluate the performance of the actuators used on the ATW.

\section{Piezoelectric Actuator Placement}

The placement of actuators on the ATW was critical to the success of the excitation system. A basic rule of thumb is to place piezoelectric actuators in regions of high average strain and away from areas of zero strain? The technique used to place the sensors for the ATW was the effective independence algorithm with strain mode shape influence coefficients. ${ }^{9}$ This technique addresses the sensor placement problem from the standpoint of a structural dynamicist who would use the data from the sensors to validate a finite-element model (FEM).

Early in the design of the ATW a baseline FEM was used for sensor placement. Based on the NASTRAN eigenvalue analysis results, the wing first-bending mode and the first-torsion mode were selected as target modes for identification. The target mode set was assumed to include all modes that are strongly excited by the actuator configuration. The shaded areas in figure 6 show the initial set of high-strain elements selected by this algorithm.

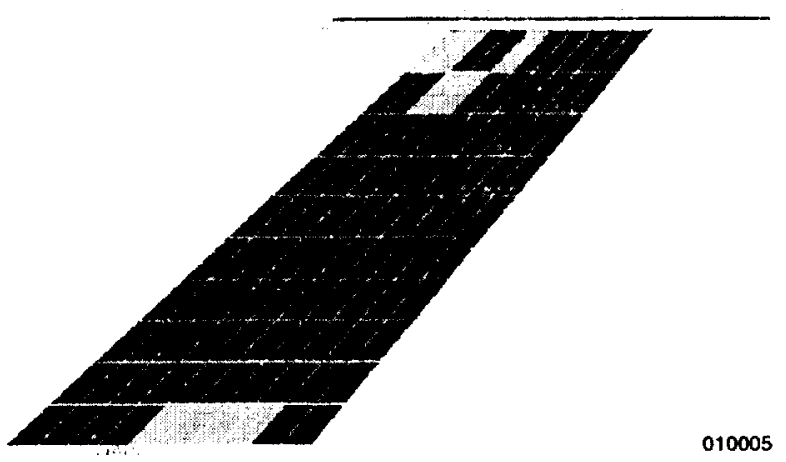

Figure 6: Initial set of elements selected for actuator locations.

These elements, selected for actuator locations, were then post-processed for visual inspection and further element set modification to account for actuator geometry. A total of six 3 -in. by 1.75 -in. by .008 -in. actuators were placed on the structure. Figure 7 shows a sketch of the piezoelectric actuators final location on the top of the wing. A mirrored set of actuators was placed on the bottom of the wing.

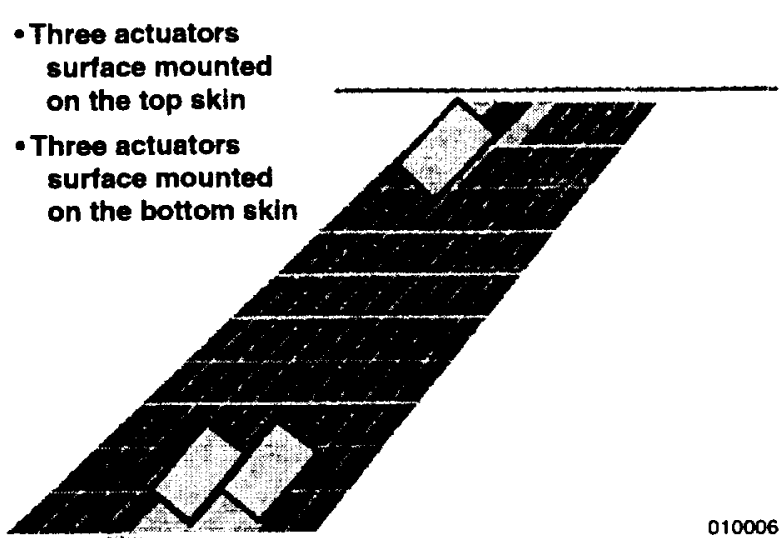

Figure 7: Final actuator configuration.

The FEM was then updated to include the piezoelectric actuators as additional layers in the original layered composite elements at the actuators locations. An eigenvalue solution of the updated FEM showed a 2-percent increase on the first-bending frequency and a 6-percent increase for the first-torsion frequency. The gain in the torsion frequency was slightly more than the goal of 5 percent, but was adequate to meet the objectives of the experiment.

\section{Amplifier}

To meet the high-voltage requirements of the piezoelectric actuators, a switching amplifier was developed (fig.5(b)). This switching amplifier can switch power supply into load at a high rate and can recover the reflective energy from the capacitive loads of the piezoelectric actuators. It has a single channel with a gain of $20 \mathrm{~V} / \mathrm{V}$ for input voltages up to $\pm 10 \mathrm{~V}$. The maximum output voltage was $\pm 200 \mathrm{~V}$. The maximum capacitive load capability was $100 \mathrm{~Hz}$ at $15 \mu \mathrm{F}$ and $20 \mathrm{kHz}$ at $1 \mu \mathrm{F}$. This was more capability than was required for the ATW, which only had a capacitive load of $1.1 \mu \mathrm{F}$ at $35 \mathrm{~Hz}$. The power into the amplifier was $28 \mathrm{~V}$ at $3 \mathrm{~A}$. The amplifier was 8 in. by $10.75 \mathrm{in}$. by $3.75 \mathrm{in}$. and weighed about $4 \mathrm{lb}$.

\section{Control Computer}

The PC-104 control computer was developed to provide an excitation signal to the piezoelectric patches on the wing (fig. 5(b)). This small computer has the capability to output $\pm 10 \mathrm{~V}$ analog signals. The computer dimensions are 5.5 in. by 5.5 in. by $6.0 \mathrm{in.}$. The computer and amplifier were mounted in the F-15B Flight Test Fixture. The signal used during the ground 
and flight tests was a constant amplitude sine sweep from $5 \mathrm{~Hz}$ to $35 \mathrm{~Hz}$. The system had the capability to vary the amplitude from $0.50 \mathrm{~V}$ to $9 \mathrm{~V}$. The signal from the control computer was sent to the amplifier, which amplified the signal by $20 \mathrm{~V} / \mathrm{V}$, and then the signal was input to the piezoelectric patches for exciting the ATW.

\section{Pilot Interface Box}

A small pilot interface box was developed to enable the pilot to select a waveform to output to the amplifier (fig 5(b)). Five momentary switches were on the box. These switches mimic the functions keys on a standard PC keyboard and allowed the pilot to select one of the five sweeps programmed into the PC-104 computer. A small display that showed the status of the sweep was also on the pilot interface box.

\section{Ground and Flight Test Overview}

The ground tests consisted of an impact ground vibration test and measuring the response of the wing to the piezoelectric excitation. The modal frequency, damping, and transfer functions were compared between the two tests. Flight test data was gathered at 21 flight conditions for both the piezoelectric excitation and with natural atmospheric turbulence. The piezoelectric actuation was compared with the excitation caused by atmospheric turbulence. A relationship was developed between the coherence of the transfer functions and the ratio of the piezoelectric and turbulence excitation.

\section{Ground Vibration Test}

\section{Impact Testing}

Impact vibration testing is a technique in which the structure being tested is excited by striking it with an instrumented impacting mass (or hammer) in order to generate a short-time duration force. ${ }^{10}$ An impact ground vibration test with the piezoelectric actuators installed was performed on the ATW to obtain response data for a baseline to compare with piezoelectric actuator excitation data. An instrumented impact hammer excited the ATW at selected test points on the wing (fig. 8). Time response data was acquired using the wingtip boom accelerometers. Frequency response functions and autospectrums were calculated from the accelerometer response data.

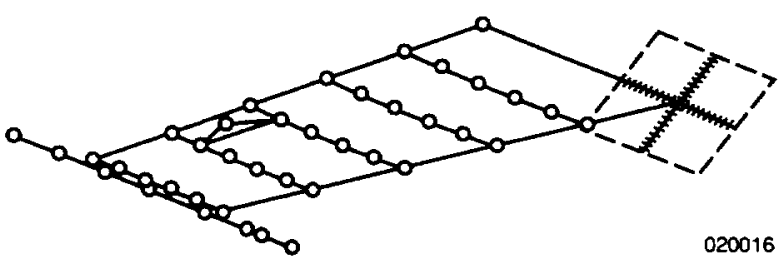

Figure 8: Impact test node points.

A single degree-of-freedom polynomial routine was used to curve fit the frequency response functions. The curve fit was used to calculate modal frequency and damping. The wing was mounted on the flight test fixture on the aircraft. During impact testing the piezoelectric actuators were not powered.

\section{Piezoelectric Actuator Testing}

A 60-sec linear sinusoidal sweep generated the excitation signal for the piezoelectric actuators. Five sweeps were programmed into the PC-104 computer that swept from 5 to $35 \mathrm{~Hz}$, each with different amplitude, $0.5 \mathrm{~V}, 1 \mathrm{~V}, 2.5 \mathrm{~V}, 5 \mathrm{~V}$, and $9 \mathrm{~V}$. The sweep was routed through the amplifier, which applied $20 \mathrm{~V} / \mathrm{V}$ amplification on the signal. The wingtip boom accelerometers were used to measure the response of the wing. Figure 9 shows a short 1 -sec time history of the sinusoidal input from the 9-volt amplitude signal amplified to $180 \mathrm{~V}$ as it passed through $14 \mathrm{~Hz}$. This figure also shows the total $60 \mathrm{sec}$ of response data for each of the programmed sweeps at each of the voltage levels.

During an aircraft ground test, each of the sweeps was run and the test data were obtained using the same aircraft instrumentation system that telemetered the data to a ground station. This ground station acquired and recorded each of the sweeps and the accelerometer response data. Voltage restrictions on the instrumentation system did not allow the high-voltage signal from the amplifier to be telemetered and recorded. Only the low-voltage signal from the PC-104 computer was used in the telemetry, as seen in figure 4 .

The frequency response functions and autospectrums from the piezoelectric actuator excitation were calculated from accelerometer time histories obtained during aircraft ground testing and from the PC-104 excitation signal.

A single degree-of-freedom polynomial routine was used to curve fit the frequency response functions. This 

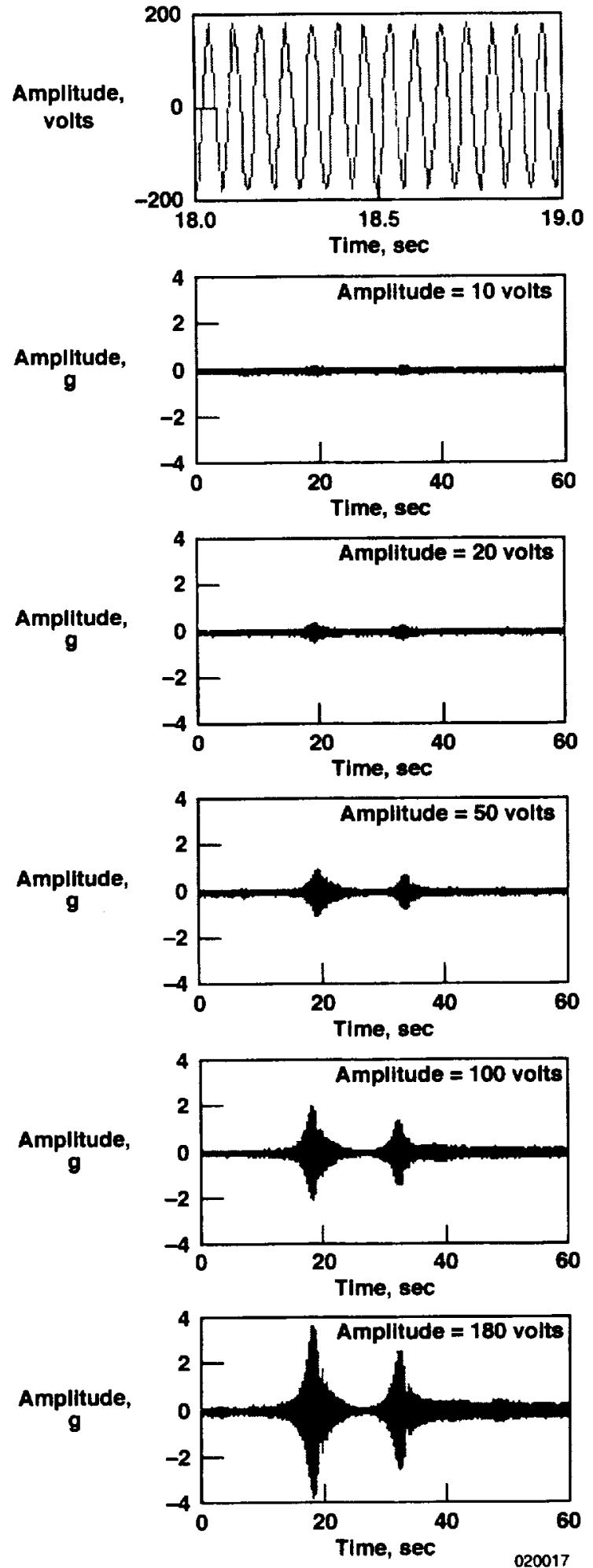

Figure 9: Excitation signal and response data. curve fit was used to calculate the modal frequency and damping.

\section{Flight Test Procedures}

Five flights of the ATW were flown during March and April 2001 at NASA Dryden Flight Research Center. These flights consisted of a system checkout flight and then four envelope expansion flights that used a series of test points with increasing dynamic pressure. Figure 10 shows the flight test points for the experiment. There were 27 test points planned during the course of the flight test, but only 21 stabilized test points where required before the wing fluttered at a Mach number of 0.83 and an altitude of $10,000 \mathrm{ft}$.

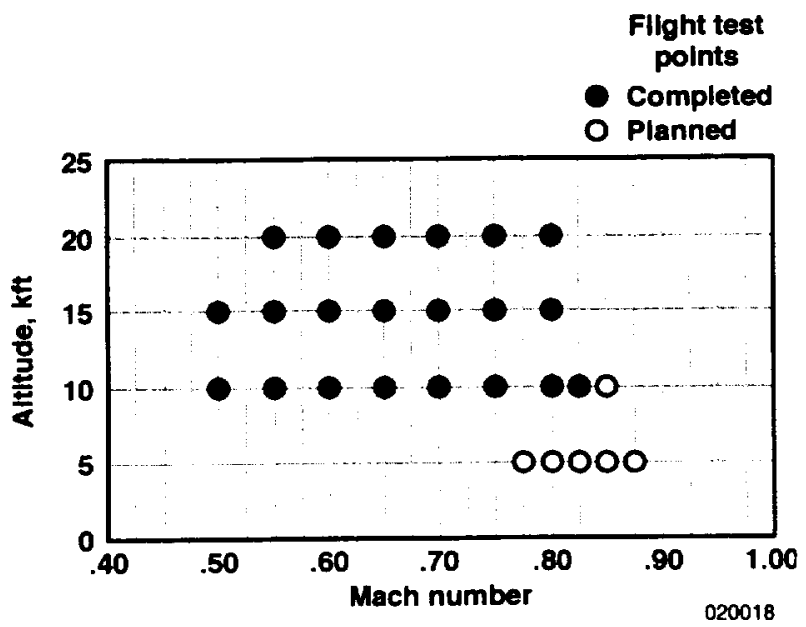

Figure 10: Flight test points for the aerostructures test wving.

At each of the 21 test points flown, the aircraft was stabilized for $30 \mathrm{sec}$ to gather information on the turbulence excitation and wing response for comparison with the piezoelectric excitation response. After the 30-sec stabilized test point, a 60 -sec linear sine sweep from $5 \mathrm{~Hz}$ to $35 \mathrm{~Hz}$ was generated by the PC-104 computer and applied to the piezoelectric actuator through the amplifier.

The responses of three accelerometers located in the wingtip boom and the pre-amplified excitation signal were telemetered to the control room, where they were monitored in real time. The flight data was also recorded for postflight analysis.

The postflight analysis consisted of calculating the frequency response functions and autospectrums from the piezoelectric excitations. Only autospectrums from 
the turbulence excitation were calculated because there was no measurement of the input force. Comparisons of the autospectrums were made between the turbulence and piezoelectric excitations.

\section{Test Results}

\section{Ground Vibration Test}

The impact test showed the most structural significance in the first-bending mode (fig 11) and the first-torsion mode (fig 12). Figure 13 shows a comparison of normalized frequency response functions from the impact test and the piezoelectric actuator excitation. Table 1 shows an estimate of frequencies and damping from the impact and actuator excitation ground tests.

Table 1. Comparison of Structural Frequency and Damping Values

\begin{tabular}{llclc}
\hline \hline Excitation & \multicolumn{2}{l}{$\begin{array}{l}\text { First Bending } \\
\text { Mechnique }\end{array}$} & \multicolumn{3}{l}{$\begin{array}{l}\text { First-Torsion } \\
\text { Mode }\end{array}$} \\
\hline & Freq., & Damp. & Freq., & Damp. \\
& $\mathrm{Hz}$ & percent & $\mathrm{Hz}$ & percent \\
Impact GVT & 13.79 & 0.4 & 20.79 & 0.6 \\
$\begin{array}{l}\text { Piezoelectric } \\
\text { Actuation }\end{array}$ & 13.81 & 0.7 & 21.00 & 0.9 \\
\hline \hline
\end{tabular}

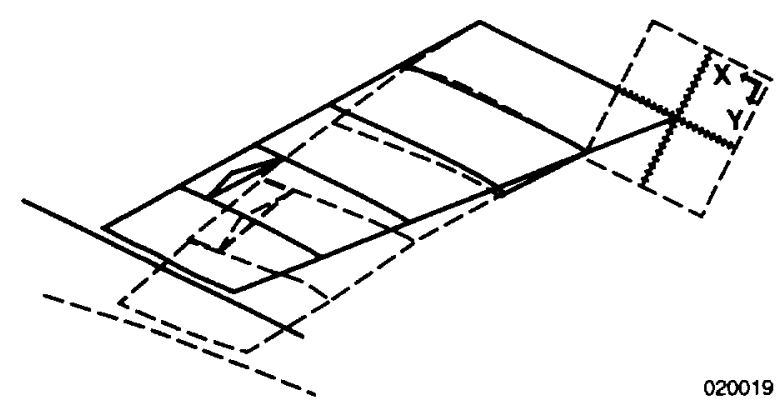

Figure 11: First-bending mode of the aerostructures test wing.

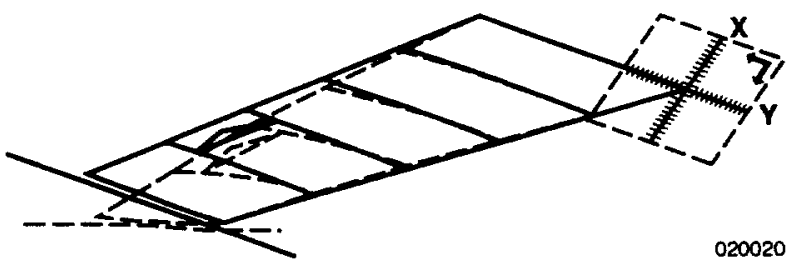

Figure 12: First-torsion mode aerostructures test wing.

Figure 13 shows good correlation exists between the impact and the piezoelectric actuation. There was a 0.1 -percent increase in first-bending frequency and a 1.0-percent increase in the first-torsion frequency from the impact to the piezoelectric excitations. The

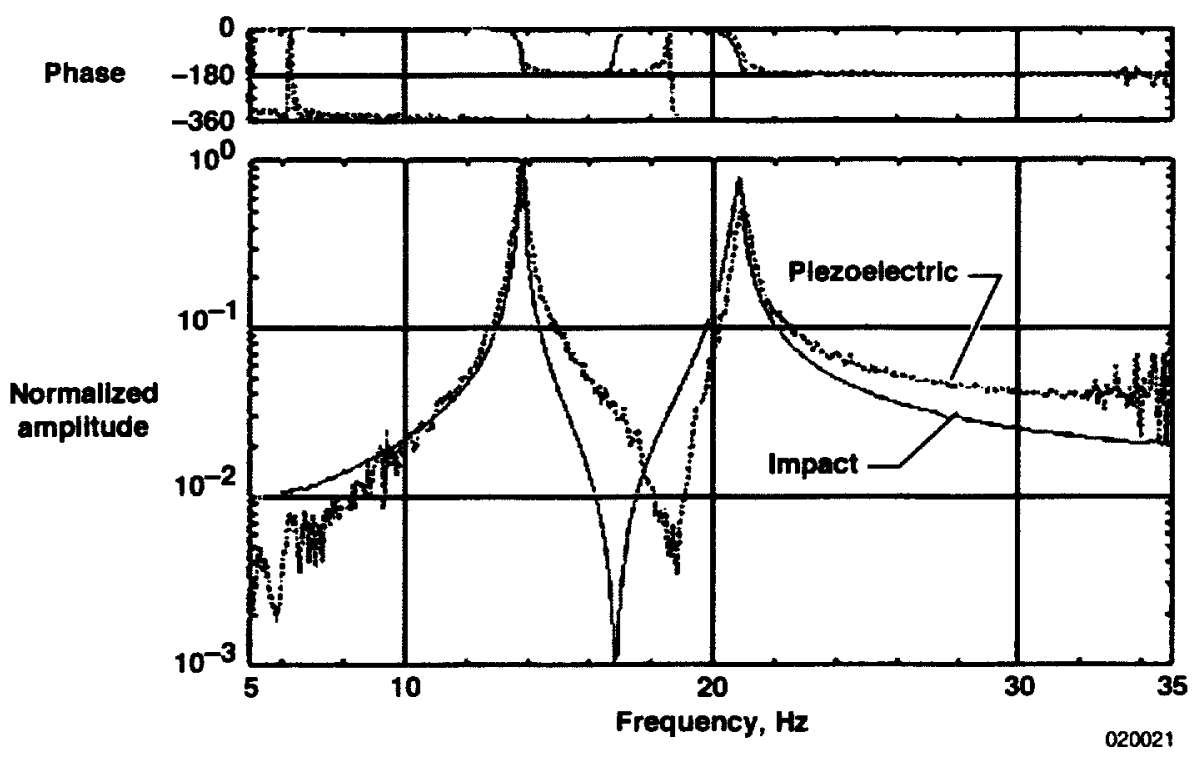

Figure 13: Comparison of normalized accelerometer frequency response functions from impact and piezoelectric excitation. 
piezoelectric actuation added damping in both structural modes. The increase in frequency is within the error bound of each testing technique and can be considered as no essential change in structural frequency. The damping increase is most likely a result of the method of excitation. Both tests were done with the piezoelectric patches installed on the wing, but the impact excitation created a sharp impulse to the structure which was allowed to decay during data acquisition. The piezoelectric excitation used a sine sweep at a rate of 0.5 $\mathrm{Hz} / \mathrm{sec}$, which does not allow the structure to fully decay at the structural frequencies before stepping to the next frequency. The sine sweep could add damping in the system.

Another result found from the piezoelectric excitation was the linear relationship between the excitation voltage and the response magnitude. Figure 14 shows how the peak resonant magnitude increases linearly with an increase in actuation voltage. The peak amplitude was about $4 \mathrm{~g}$ 's at the $180 \mathrm{~V}$ input signal for the wing-bending mode and about $2.5-\mathrm{g}$ 's for the torsion mode.

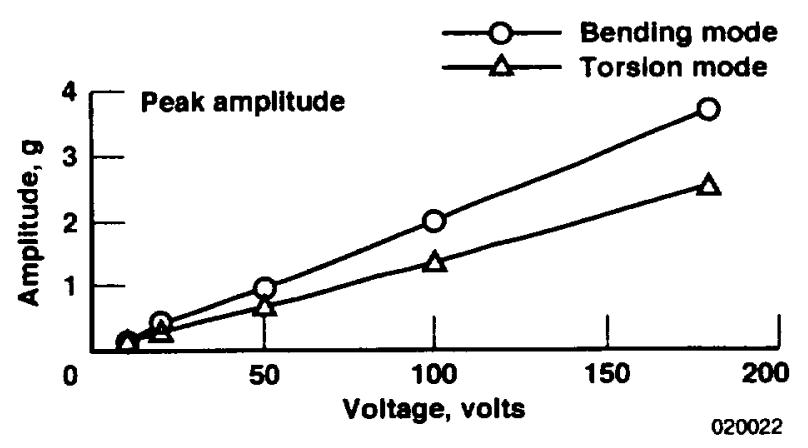

Figure 14: Resonate magnitude changes with increasing excitation voltage.

\section{Flight Performance of the Piezoelectric Excitation}

Piezoelectric actuation and turbulence data was acquired for each of the 21 test points flown during the ATW flights. Figure 15 and 16 show a normalized transfer function from the wing aft boom accelerometer to the PC-104 excitation signal at a Mach number of 0.60 and an altitude of $20,000 \mathrm{ft}$ and at a Mach number of 0.80 and an altitude of $10,000 \mathrm{ft}$, respectively. Also figure 15 and 16 show the coherence function. The coherence function is a measure of the linearity of the output to the input at each frequency and is rated on a $\mathbf{0}$ to 1 scale. When this ratio of output to input is totally

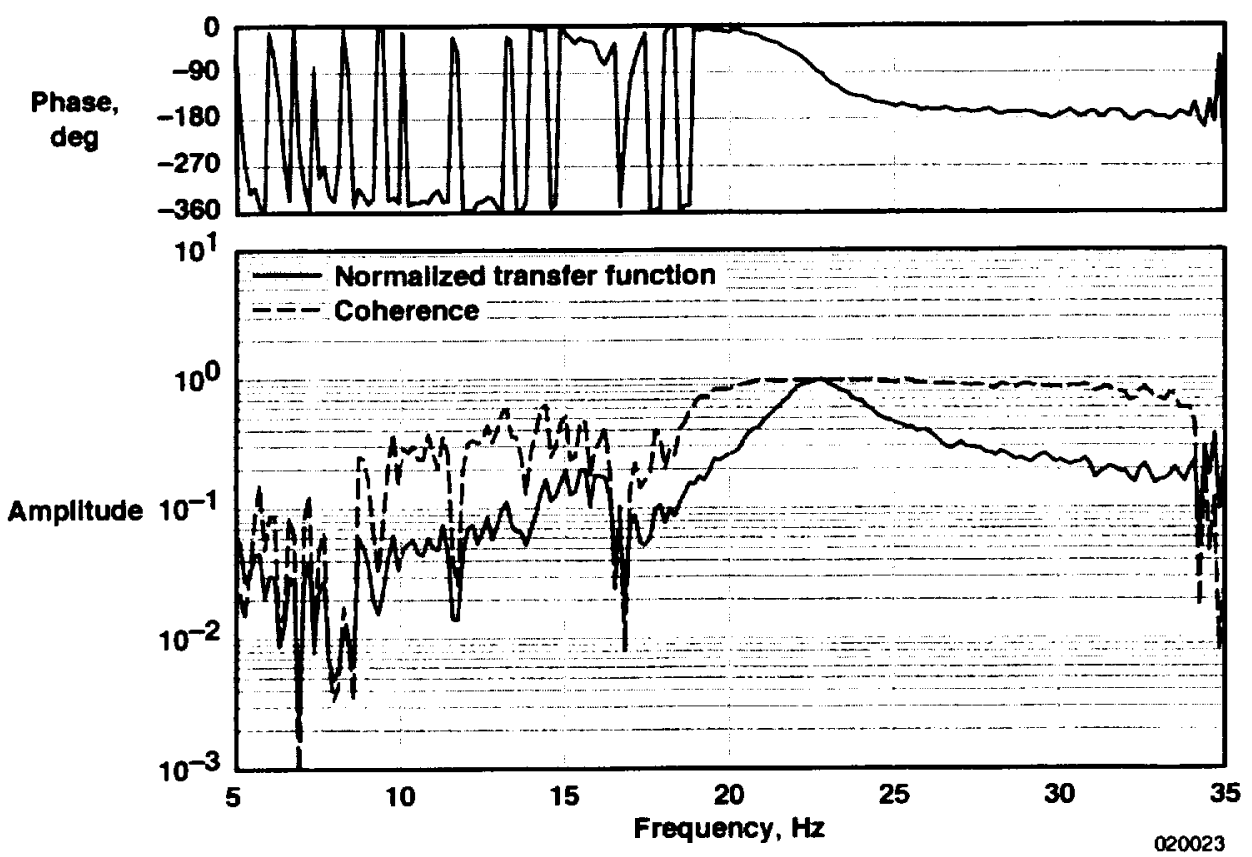

Figure 15: Normalized frequency response function with coherence at a Mach number of 0.60 and an altitude of $20,000 \mathrm{ft}$. 


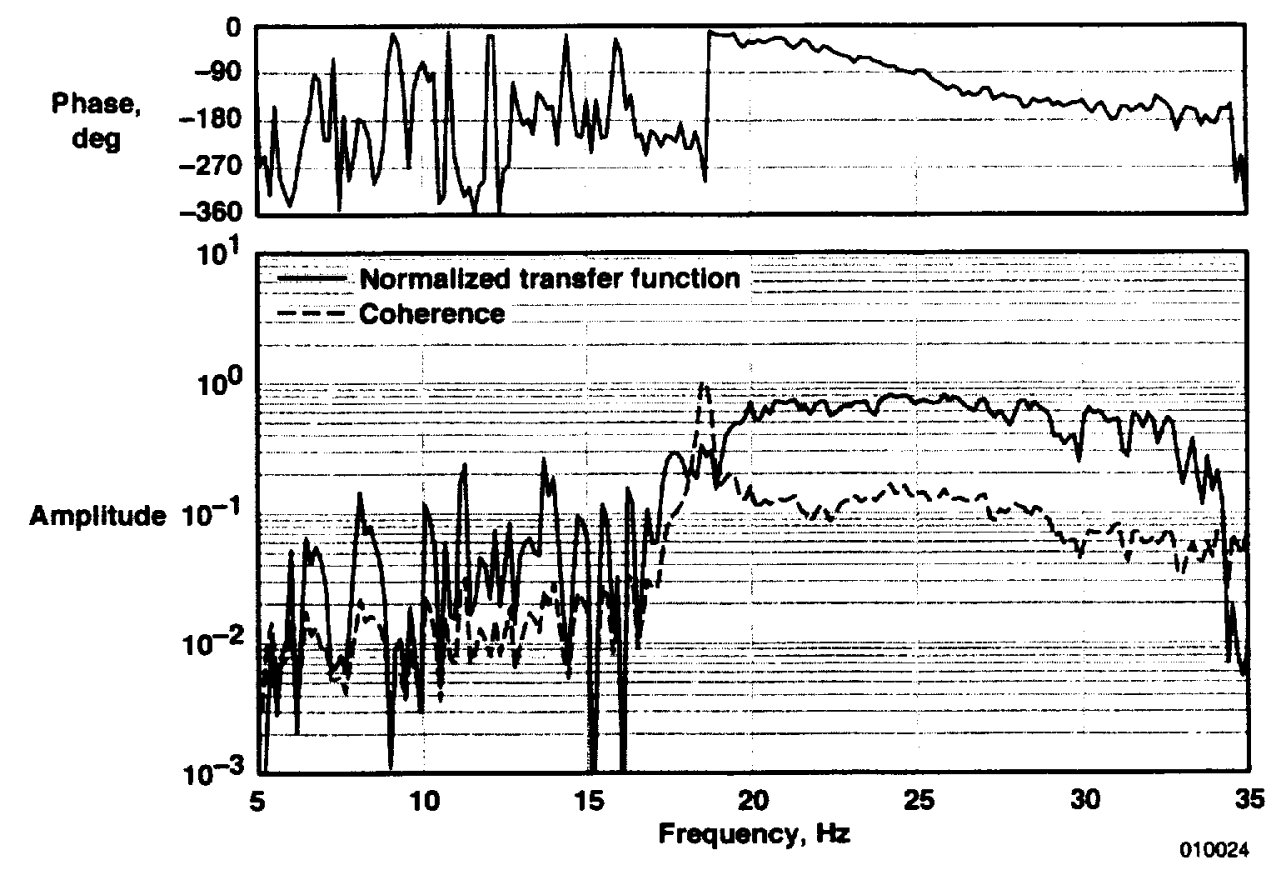

Figure 16: Normalized frequency response function with coherence at a Mach number of 0.80 and an altitude of $10,000 \mathrm{ft}$.

correlated at a certain frequency, the coherence is 1 . In the presence of noise or other inputs the coherence will be less than one, or in the case of totally uncorrelated output to input the coherence could be zero.

At the low dynamic pressure in figure 15 , the transfer function shows a moderately damped torsion mode at $22 \mathrm{~Hz}$. The coherence function indicates that this mode is well correlated with the piezoelectric excitation. At this flight condition, the transfer function is not showing a lower frequency mode. At the higher dynamic pressure point shown in figure 16 , the coherence function above $20 \mathrm{~Hz}$ is indicating about a 65-percent correlation of the wing response to the piezoelectric excitation. But, because the mode above $20 \mathrm{~Hz}$ is highly damped it does have a large amplitude response. The first-bending mode shows a large amplitude response at $18 \mathrm{~Hz}$, but the coherence at this frequency' is poor.

These changes in the structure are a result of the aerodynamic effects acting on the structure. These effects cause the two modes to come together, which in turn creates the flutter of the wing. The $18 \mathrm{~Hz}$ structural response is the result of this coalescence of the bending and torsion modes.
The autospectrums of the turbulence and piezoelectric excitation in figures 17 and 18 show some of the reasons for the poor coherence. Figure 17 shows the autospectrums for a Mach number of 0.60 at an altitude of $20,000 \mathrm{ft}$. The turbulence is exciting the first-bending mode as well as the piezoelectric excitation while at the higher frequencies, turbulence is creating little or no response in the structure. At the higher dynamic pressure shown in figure 18 , both turbulence and piezoelectric excitation are creating about the same level of response in the wing at the structural frequency. Figure 19 shows the RMS acceleration at 9 different flight conditions from 5 to $35 \mathrm{~Hz}$. The data shows that the piezoelectric excitation created a higher response in the wing throughout the envelope. But, the figure also shows that the turbulence levels increased with similar trends to the piezoelectric excitation.

In order to better understand the relationship of the piezoelectric excitation, turbulence levels, and the quality of the transfer functions, a signal-to-noise ratio was created and a relationship to coherence was developed. The autospectrums in figures 17 and 18 were divided into six frequency ranges, $5-10 \mathrm{~Hz}$, $10-15 \mathrm{~Hz}, \quad 15-20 \mathrm{~Hz}, 20-25 \mathrm{~Hz}, 25-30 \mathrm{~Hz}$, and $30-35 \mathrm{~Hz}$. In each frequency range root mean square 


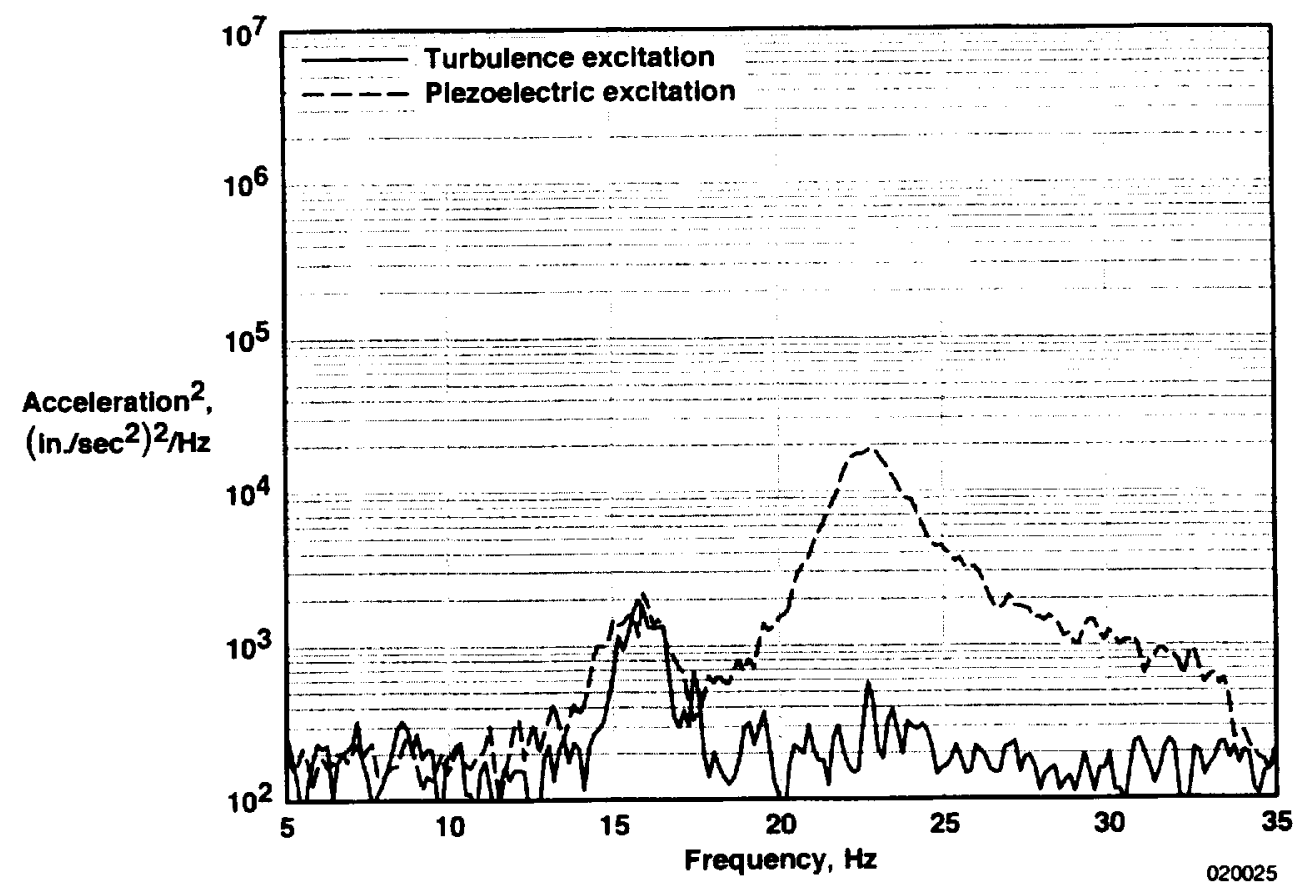

Figure 17: Spectrums of accelerometer response with and without piezoelectric excitation (at a Mach number of 0.60 and an altitude of $20,000 \mathrm{ft}$ ).

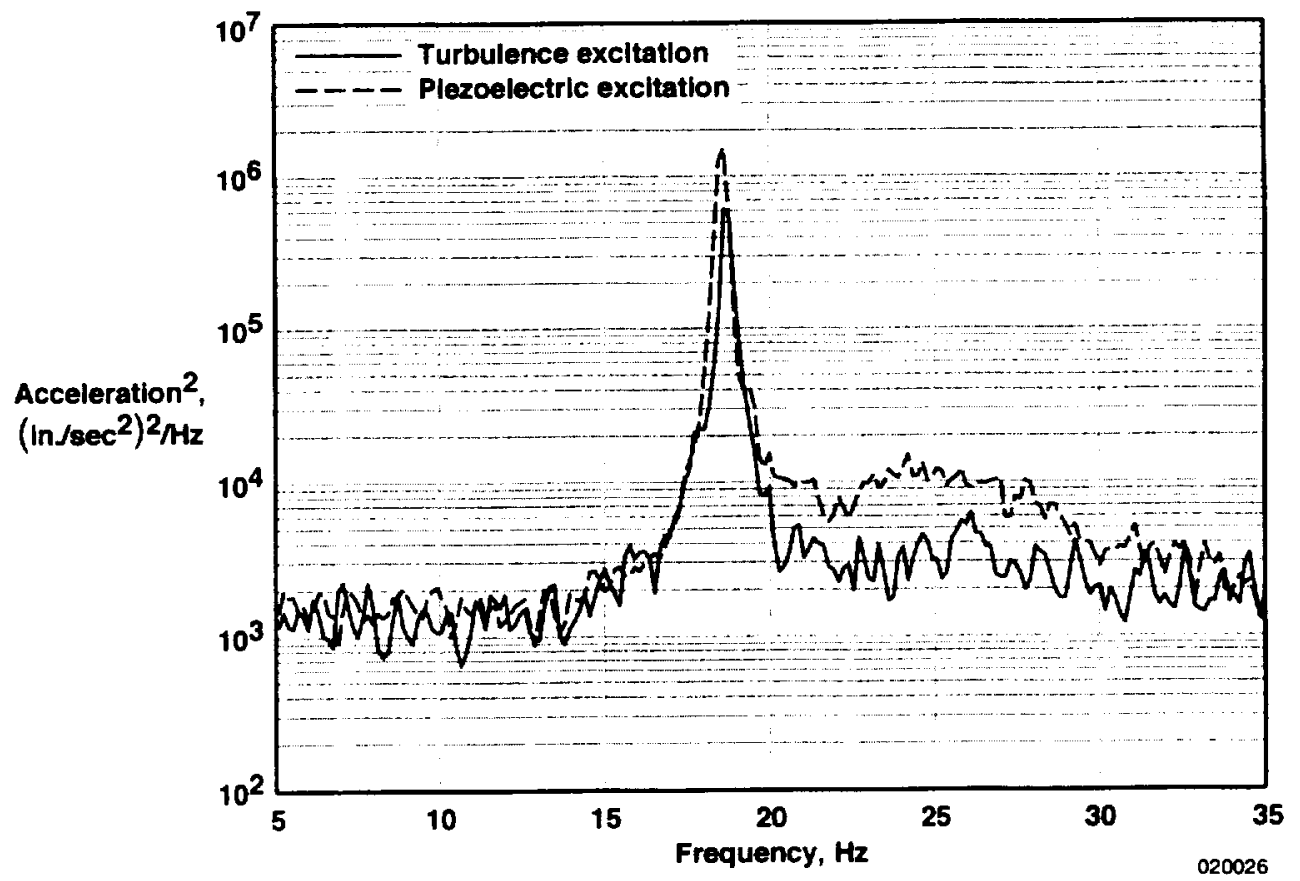

Figure 18: Autospectrums of accelerometer response with and without piezoelectric excitation (at a Mach number of 0.80 and an altitude of $10,000 \mathrm{ft}$ ). 


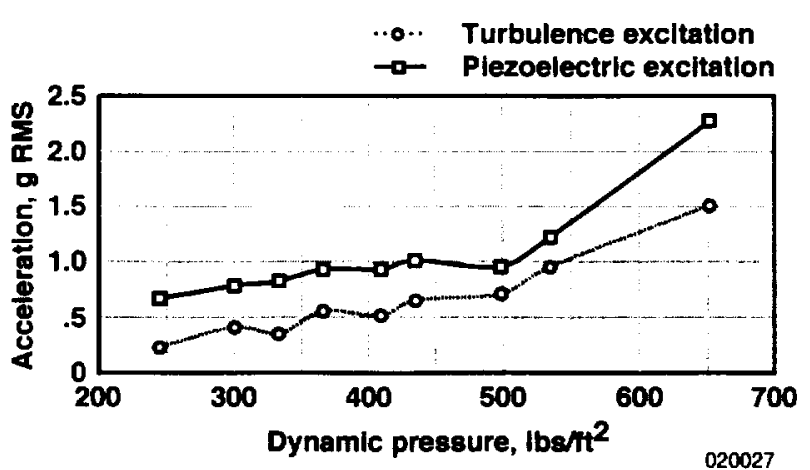

Figure 19: Root mean square acceleration for piezoelectric and turbulence excitation.

(RMS) acceleration was calculated for the piezoelectric and turbulence excitations. These RMS accelerations were divided to create a piezoelectric to turbulence (PT) RMS ratio. In the same frequency ranges, the coherence from figures 15 and 16 were averaged. The average coherence was then graphed to the PT RMS ratio in figure 20.

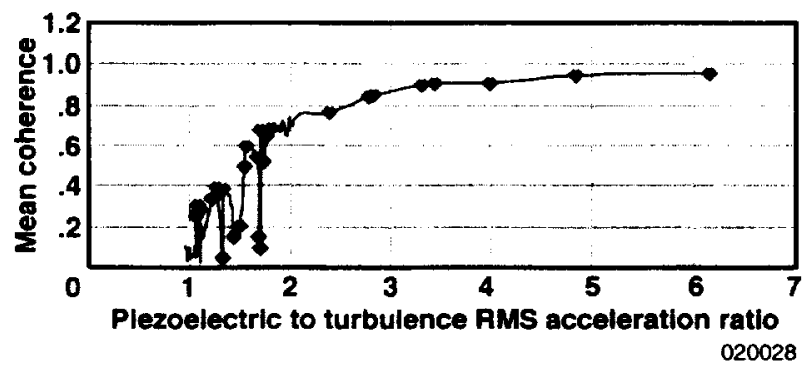

Figure 20: Coherence relationship to PT-RMS ratio.

Figure 20 shows that to reach coherence above 0.6 , the PT RMS ratio would have to be above 1.5. An acceptable coherence for signal processing would be above $\mathbf{0 . 8 0}$. In order to get a 0.80 coherence, a PT RMS ratio would have to be over 3.0. A good coherence for signal processing would be above 0.90 . To achieve this level, the PT RMS ratio would have to be above 3.5 . Also from figure 20 it can be seen there is not much gain in the coherence of the transfer function above the 3.5 PT RMS ratio.

\section{Conclusions}

This paper demonstrates how piezoelectric actuators were used in an excitation system for a ground and flight experiment that was conducted at NASA Dryden Flight Research Center. Ground vibration testing (GVT) was done on the wing at the same time as performance characterization of the actuators. Response data from the GVT using the piezoelectric excitation compared well with the impact excitation technique. The autospectrums showed less than a 1-percent frequency change in the first-bending and first-torsion structural modes. The damping was about 3-percent higher for the two main structural modes, but this may have been a result of using sinusoidal sweeps comparing damping to an impact excitation technique. There was a linear relationship between the piezoelectric input voltages to amplitude of the resonant modal responses.

The piezoelectric excitation during flight consistently created an increased response level in the structure. However, an increased response did not always generate a more efficient transfer function that could be used effectively in signal processing. The coherence function was used as a measure of the quality of the transfer function. In order to get a good coherence above 0.90 , the piezoelectric excitation level had to be approximately 3.5 times that of the turbulence levels. Stability algorithms that rely on the transfer function data should incorporate some uncertainties to account for the poor coherence and transfer functions.

In flight flutter testing, it is important that all critical structural modes be observable at higher dynamic pressures. Where the turbulence levels were high, the autospectrums did not differ much from the piezoelectric excitation, showing that turbulence might have been good enough for basic frequency and damping calculations. But, at the lower dynamic pressures, the turbulence levels were not enough to excite the torsion mode of the wing, whereas the piezoelectric excitation increased this mode by one order of magnitude or greater. Only the piezoelectric excitation was able to excite these two structural modes throughout the desired flight envelope, which is critical for any flight stability estimates.

\section{References}

${ }^{1}$ Richwine, David M, F-15B/Flight Test Fixture II: A Test Bed for Flight Research. NASA TM 4782, December 1996.

${ }^{2}$ Kehoe, Michael W., A Historical Overview of Flight Flutter Testing, NASA TM 4720, October 1995.

${ }^{3}$ McGowan, Anna-Maria R., Heeg, Jennifer, and Lake, Renee C. "Results of Wind-Tunnel Testing From 
the Piezoelectric Aeroelastic Response Tailoring Investigation" 37th AIAA/ASME/ASCE/AHS/ASC Structural Dynamics and Materials Conference, A Collection of Technical Papers, Salt I ake City, UT April 15-17, 1996.

${ }^{4}$ Moses, Robert W., Vertical Tail Buffeting Alleviation Using Piezoelectric Actuators - Some Results of the Actively Controlled Response of Buffet-Affected Tails (ACROBAT) Program, NASA Technical Memorandum 110336, April 1997.

${ }^{5}$ Wilkie, W. K., Bryant, R. G., High, J. W., Fox, R. L., Hellbaum, R. F., Jalink, A., Jr., Little. B. D., and Mirick, P. H., "Low-Cost Piezocomposite Actuator for Structural Control Applications," SPIE's 7th Annual International Symposium on Smart Structures and Materials, Newport Beach, CA, March 5-9, 2000.

${ }^{6}$ Falangas, Eric T., Charles R. Larson, Joseph S. Rosenthall, Melvin Weiss, and Demetrious G. Zeferis, Piezoceramic Actuator Active Vibration Suppression System B-1B Flight Demonstration Program, AFRLVA-WP-TR-1999-3011, January 1998.

${ }^{7}$ Crawley, Edward F. and deLuis, Javier, "Use of Piezoelectric Actuators as Elements of Intelligent Structures", AIAA Journal, Volume 25, Number 10, October 1987.

${ }^{8}$ M. C. Brennan and A. R. McGowan, "Piezoelectric Power Requirements for Active Vibration Control", SPIE Proceedings of the 4th Annual Symposium on Smart Structures and Materials, San Diego, California, March 3-6, 1997.

${ }^{9}$ Kammer, Daniel C., "Sensor Placement for On-Orbit Modal Identification and Correlation of Large Space Structures", Journal of Guidance, Control, and Dynamics, Vol. 14, No. 2, 1991, pp.251-259.

${ }^{10}$ McConnell, Kenneth G., Vibration Testing: Theory and Practice, John Wiley and Sons, Inc. 1995. 
Public reporting burden tor this collection of information is estimated to average 1 hour per response, including the time tor reviewing instructions, searching existing data sources. gathering and maintaining the data needed, and completing and reviewing the collection of information. Send comments regarding this burden estimate or any other aspect of this collection of intormation, including suggestions tor reducing this burden, 10 Washington Headquarters Services, Directorate for Intormation Operations and Reports, 1215 Jefferson Davis Highway. Suite 1204 . Arlington, VA 22202-4302, and to the Ottice of Management and Budget, Paperwork Reduction Project (0704-0189). Washington, DC 20503

\begin{tabular}{|l|c|c|}
\hline 1. AGENCY USE ONLY (Leave blank) & $\begin{array}{c}\text { 2. REPORT DATE } \\
\text { April 2002 }\end{array}$ & $\begin{array}{l}\text { 3. REPORT TYPE AND DATES COVERED } \\
\text { Technical Memorandum }\end{array}$ \\
\hline
\end{tabular}

4. TITLE AND SUBTITLE

Ground and Flight Test Structural Excitation Using Piezoelectric Actuators

6. AUTHOR(S)

036-00-00-E8-RR-00P-DDF

David F. Voracek, Mercedes Reaves, Lucas G. Horta and Starr Potter

8. PERFORMING ORGANIZATION

REPORT NUMBER

NASA Dryden Flight Research Center

P.O. Box 273

Edwards, California 93523-0273

H-2482

9. SPONSORINGMONTORING AGENCY NAME(S) AND ADDRESS(ES)

10. SPONSORINGNONITOAING

AGENCY REPORT NUMBER

National Aeronautics and Space Administration

Washington, DC 20546-0001

NASA TM-2002-210724

\section{SUPPLEMENTARY NOTES}

Also presented at the 43rd AIAA/ASME/ASCE/AHS/ASC Structures, Structural Dynamics and Materials Conference, April 22-25, 2002, Denver Colorado. AIAA-2002-1349

\begin{tabular}{l|l}
\hline 12a. DISTRIBUTIONAVAILABILITY STATEMENT & 12b. DISTRIBUTION CODE \\
Unclassified - Unlimited & \\
Subject Category 02 & \\
This report is available at http://www.dfrc.nasa.gov/DTRS/ &
\end{tabular}

13. ABSTRACT (Maximum 200 words)

A flight flutter experiment at the National Aeronautics and Space Administration (NASA) Dryden Flight Research Center, Edwards, Califomia, used an 18-inch half-span composite model called the Aerostructures Test Wing (ATW). The ATW was mounted on a centerline flight test fixture on the NASA F-15B and used distributed piezoelectric strain actuators for in-flight structural excitation. The main focus of this paper is to investigate the performance of the piezoelectric actuators and test their ability to excite the first-bending and first-torsion modes of the ATW on the ground and in-flight. On the ground, wing response resulting from piezoelectric and impact excitation was recorded and compared. The comparison shows less than a 1-percent difference in modal frequency and a 3-percent increase in damping. A comparison of in-flight response resulting from piezoelectric excitation and atmospheric turbulence shows that the piezoelectric excitation consistently created an increased response in the wing throughout the flight envelope tested. The data also showed that to obtain a good correlation between the piezoelectric input and the wing accelerometer response, the input had to be nearly 3.5 times greater than the turbulence excitation on the wing.

\begin{tabular}{|c|c|c|c|}
\hline \multicolumn{3}{|c|}{$\begin{array}{l}\text { 14. SUBJECT TERMS } \\
\text { Piezoelectrics, Structural Excitation, Flutter, Actuators, Flight Test }\end{array}$} & \begin{tabular}{|c|} 
15. NUMBER OF PAGES \\
16 \\
$\begin{array}{c}\text { 16. PRICE CODE } \\
\text { A03 }\end{array}$ \\
\end{tabular} \\
\hline $\begin{array}{l}\text { 17. SECUAITY CLASSIFICATION } \\
\text { OF REPORT }\end{array}$ & $\begin{array}{l}\text { 18. SECUAITY CLASSIFICATION } \\
\text { OF THIS PAGE }\end{array}$ & $\begin{array}{l}\text { 19. SECURITY CLASSIFICATION } \\
\text { OF ABSTRACT }\end{array}$ & 20. LIMTTATION OF ABSTAACT \\
\hline Unclassified & Unclassified & Unclassified & Unlimited \\
\hline
\end{tabular}

